ORIGINAL ARTICLE

\title{
Can an airway assessment score predict difficulty at intubation in the emergency department?
}

\author{
M J Reed, M J G Dunn, D W McKeown
}

Emerg Med J 2005;22:99-102. doi: 10.1136/emj.2003.008771

\begin{abstract}
See end of article for authors' affiliations

.....................

Correspondence to:

Dr M J Reed, Emergency

Department, Royal

Infirmary of Edinburgh,

51 Little France Crescent

Edinburgh EH16 4SA, UK;

mattreed1@hotmail.com

Accepted for publication

9 December 2003
\end{abstract}

\begin{abstract}
Aim: To assess whether an airway assessment score based on the LEMON method is able to predict difficulty at intubation in the emergency department.

Methods: Patients requiring endotracheal intubation in the resuscitation room of a UK teaching hospital between June 2002 and September 2003 were assessed on criteria based on the LEMON method. At laryngoscopy, the Cormack and Lehane grade was recorded. An airway assessment score was devised and assessed.

Results: 156 patients were intubated during the study period. There were 114 Cormack and Lehane grade 1 intubations, 29 grade 2 intubations, 11 grade 3 intubations, and 2 grade 4 intubations. Patients with large incisors $(p<0.001)$, a reduced inter-incisor distance $(p<0.05)$, or a reduced thyroid to floor of mouth distance $(p<0.05)$ were all more likely to have a poor laryngoscopic view (grade 2, 3, or 4). Patients with a high airway assessment score were more likely to have a poor laryngoscopic view compared with those patients with a low airway assessment score $(p<0.05)$.

Conclusions: An airway assessment score based on criteria of the LEMON method is able to successfully stratify the risk of intubation difficulty in the emergency department. Patients with a poor laryngoscopic view (grades 2, 3, or 4) were more likely to have large incisors, a reduced inter-incisor distance, and a reduced thyroid to floor of mouth distance. They were also more likely to have a higher airway assessment score than those patients with a good laryngoscopic view.
\end{abstract}

$\mathrm{T}$ ere is a growing trend in the UK for advanced airway management to be performed in the emergency department (ED) resuscitation room by ED clinicians, rather than anaesthetists. The need for tracheal intubation in the ED may be unpredictable and is often promptly required. When compared with the same procedure performed in the operating room, a higher incidence of airway management failure has been suggested. ${ }^{1}$ Some $0.01 \%$ of patients intubated electively will have an airway management failure compared with an ED rescue cricothyrotomy rate of $1 \%$ in the pilot phase of the National Emergency Airway Registry (NEAR) studies. ${ }^{1}$ It is suggested that patients intubated in the ED have poorer views on laryngoscopy measured by higher Cormack and Lehane scores. ${ }^{23}$

The historical information, physical examination findings, and radiological features associated with a difficult airway are well established. Proposed airway assessment scales vary from the simple, which often fail to address the many factors associated with a difficult airway, to the complex, which are impractical as a clinical tool. None have been shown to be accurate in predicting airway management problems, and none have been assessed in the ED setting. The physical characteristics associated with difficult intubation include obesity, ${ }^{4-8} 1012$ head and neck movement, ${ }^{46-12}$ jaw movement, ${ }^{46}$ receding mandible, ${ }^{46711}$ buck teeth (long upper incisors ), ${ }^{4612}$ Mallampatti scores, ${ }^{568-12}$ maxillary incisor characteristics, ${ }^{7}$ male sex, ${ }^{8}$ age $40-59,{ }^{8}$ decreased mouth opening, ${ }^{8}{ }^{10-12}$ shortened thyromental distance, ${ }^{58-11}$ and short neck. ${ }^{7}$ Multivariate analysis has been used to quantify the relative role of each of these physical characteristics. ${ }^{10-12}$

An assessment system that objectively measures factors associated with a difficult intubation in the resuscitation room needs to be simple to perform, suitable to perform on obtunded and/or non-compliant patients, and easily remembered. All of the above systems fail to be suitable when applied in an ED setting.
The US National Emergency Airway Management Course has addressed this issue by devising the LEMON method (fig 1). ${ }^{1}$ This assessment system includes most of the characteristics discussed above and has been adapted for use in a resuscitation room setting. The LEMON method has not however been validated as a reflection of difficult intubation in the ED.

The aim of this study was therefore to assess whether an airway assessment score based on the LEMON method is able to predict difficulty at intubation in the ED.

\section{METHOD}

This was a prospective observational study conducted in the ED of a UK teaching hospital between June 2002 and September 2003. All patients who entered one of the department's resuscitation rooms underwent an airway assessment according to the LEMON method (fig 1). They were assessed on four "look" criteria, three "evaluate" criteria, the presence of airway obstruction, and neck mobility. Mallampatti class ${ }^{13}$ was also recorded if possible. Only four of the seven "look" characteristics originally described in the LEMON method were assessed: "abnormal facial shape" was thought to be too subjective, "protruding teeth" is duplicated by the "large incisor" characteristic, and "false teeth" is often difficult to assess adequately. If intubation was performed as part of the patient's routine clinical management, the grade of intubation was recorded according to Cormack and Lehane scores. ${ }^{14}$ For the purposes of this study, an easy intubation was defined as a Cormack and Lehane laryngoscopy grade 1 view, and a difficult intubation was defined as a Cormack and Lehane laryngoscopy grade 2, 3, or 4 view (see Discussion). If an initial intubation attempt was unsuccessful, the grade of laryngoscopy on the eventual successful attempt was used to define the difficulty of intubation. 
L Look externally

Look at the patient externally for characteristics that are known to cause difficult laryngoscopy, intubation or ventilation.

\section{E Evaluate the 3-3-2 rule}

In order to allow alignment of the pharyngeal, laryngeal and oral axes and therefore simple intubation, the following relationships should be observed. The distance between the patient's incisor teeth should be at least 3 finger breadths (3), the distance between the hyoid bone and the chin should be at least 3 finger breadths (3), and the distance between the thyroid notch and the floor of the mouth should be at least 2 finger breadths (2).

$1=$ Inter-incisor distance in fingers.

$2=$ Hyoid mental distance in fingers.

$3=$ Thyroid to floor of mouth in

fingers.

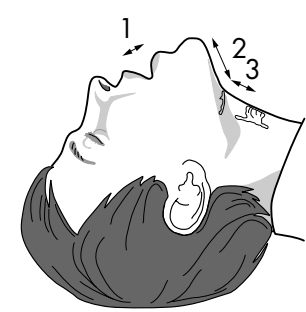

M Mallampati

The hypopharynx should be visualized adequately. This has been done traditionally by assessing the Mallampati classification. The patient is sat upright, told to open the mouth fully and protrude the tongue as far as possible. The examiner then looks into the mouth with a light torch to assess the degree of hypopharynx visible. In the case of a supine patient, Mallampati score can be estimated by getting the patient to open the mouth fully and protrude the tongue and a laryngoscopy light can be shone into the hypopharynx from above.

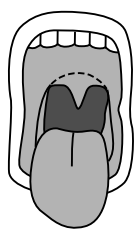

Class I: soft palate, uvula, fauces, pillars visible

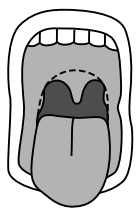

Class II: soft palate, uvula, fauces visible

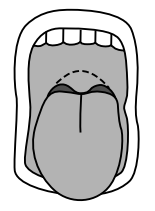

Class III: soft palate, base of uvula visible
Figure 1 The LEMON airway assessment method.

O Obstruction?

Any condition that can cause obstruction of the airway will make laryngoscopy and ventilation difficult. Such conditions are epiglottis, peritonsillar abscesses and trauma.

$\mathrm{N}$ Neck mobility

This is a vital requirement for successful intubation. It can be assessed easily by getting the patient to place their chin down onto their chest and then to extend their neck so they are looking towards the ceiling. Patients in hard collar neck immobilization obviously have no neck movement are therefore harder to intubate.

An airway assessment score was calculated as follows. The number of positive "look" criteria was calculated. One point was added for each unfavourable "evaluate" criteria (mouth opening less than three finger breadths, hyo-mental distance less than three finger breadths, or a thyro-hyoid distance less than two finger breadths). One point was also added for a Mallampatti score of 3 or more, for an obstructed airway, and for poor neck mobility. If a test could not be performed the patient received a score of zero for that criterion. The maximum airway assessment score possible was therefore 10 and the minimum zero.

All data were entered on a form and completed forms were collected for data entry and analysis using Microsoft Excel. Fisher's exact test was used to compare categorical variables and Student's $t$ test for parametric data. Spearman's rank sum test was used to assess correlation between categorical variables. Significance was defined as $\mathrm{p}<0.05$.

\section{RESULTS}

Between June 2002 and September 2003, 156 patients who were intubated in the ED were entered into the study. This comprised $88 \%$ of the 177 patients undergoing intubation in the department during this period. Patients who were lost from the study did not have a formal airway assessment performed at the time of intubation. All 156 patients were successfully intubated in the ED.

Altogether 114 patients were characterised as Cormack and Lehane grade 1 and 42 were classed as Cormack and Lehane grades 2,3 , or 4 (grade $2=29$, grade $3=11$, and grade $4=2$ ). Table 1 compares the characteristics of patients with an easy intubation (grade 1) compared with those with a difficult intubation (grades 2, 3, and 4).

There was no significant difference in the sex ratios $(M / F)$ between the two groups (75/39 compared with 32/10, $\mathrm{p}=0.25$, NS). There was also no difference in mean age between the two groups (53.8 years compared with 55.7 years, $\mathrm{p}=0.86$, NS).

Of the three "look" criteria of the LEMON method, only patients with large incisors $(\mathrm{p}<0.001)$ were more likely to have a difficult intubation (grade 2,3 , or 4 ). There was no difference in intubation grade in patients with facial trauma $(p=1.0, N S)$, a beard or moustache $(p=0.49, N S)$, or a large tongue ( $p=0.49$, NS). Of the three "evaluate" criteria, both a reduced inter-incisor distance $(\mathrm{p}<0.05)$ and a reduced thyroid to floor of mouth distance $(p<0.05)$ were associated with a difficult intubation. There was no significant difference in intubation grade in patients with a reduced hyoid to chin distance ( $p=0.34$, NS) however $45.8 \%$ of patients in the 


\begin{tabular}{|c|c|c|c|c|c|}
\hline Characteristic & $\begin{array}{l}\text { Easy intubation } \\
\text { group }\end{array}$ & Number & $\begin{array}{l}\text { Difficult intubation } \\
\text { group }\end{array}$ & Number & $p$ Value \\
\hline Number of patients & 114 & - & 42 & - & - \\
\hline \multirow[t]{2}{*}{$\begin{array}{l}\text { Sex ratio (M/F) } \\
\text { Male percentage }\end{array}$} & $\begin{array}{l}75 / 39 \\
65.8\end{array}$ & 114 & $\begin{array}{l}32 / 10 \\
76.2\end{array}$ & 42 & $0.25 \mathrm{NS}+$ \\
\hline & Mean (SD) & & Mean (SD) & & \\
\hline Age & $53.8(23.2)$ & 114 & $55.7(18.7)$ & 42 & 0.86 NSt \\
\hline Look & $\%$ & & $\%$ & & \\
\hline Facial trauma & 11.3 & 106 & 12.2 & 41 & $1.0 \mathrm{NS}+$ \\
\hline Large incisors & 6.5 & 108 & 28.6 & 42 & $<0.001 * \dagger$ \\
\hline Beard or moustache & 6.3 & 111 & 9.8 & 41 & $0.49 \mathrm{NS}+$ \\
\hline Large tongue & 1.0 & 104 & 2.4 & 41 & $0.49 \mathrm{NS}+$ \\
\hline Evaluate & $\%$ & & $\%$ & & \\
\hline $\begin{array}{l}\text { Incisor distance 3+ } \\
\text { Incisor distance }<3\end{array}$ & $\begin{array}{l}61.8 \\
38.2\end{array}$ & 76 & $\begin{array}{l}31.0 \\
69.0\end{array}$ & 29 & $<0.05 * \dagger$ \\
\hline $\begin{array}{l}\text { Hyoid / mental dist 3+ } \\
\text { Hyoid / mental dist <3 }\end{array}$ & $\begin{array}{l}65.8 \\
34.2\end{array}$ & 76 & $\begin{array}{l}54.2 \\
45.8\end{array}$ & 24 & $0.34 \mathrm{NS}+$ \\
\hline Thyroid to mouth $2+$ & $\begin{array}{l}86.6 \\
134\end{array}$ & 82 & $\begin{array}{l}58.3 \\
412\end{array}$ & 24 & $<0.05^{\star} \dagger$ \\
\hline $\begin{array}{l}\text { Thyroid to mouth }<2 \\
\text { Mallampatti }\end{array}$ & $\begin{array}{l}13.4 \\
\%\end{array}$ & & $\begin{array}{l}41.2 \\
\%\end{array}$ & & \\
\hline Grade 1 or 2 & 67.2 & 67 & 78.9 & 19 & $0.41 \mathrm{NS}+$ \\
\hline Grade 3 or 4 & 32.8 & & 21.1 & & \\
\hline Obstruction & $\%$ & & $\%$ & & \\
\hline Obstructed airway & 6.5 & 108 & 14.3 & 42 & $0.19 \mathrm{NS}+$ \\
\hline $\begin{array}{l}\text { Neck mobility } \\
\text { In collar/limited }\end{array}$ & $\begin{array}{l}\% \\
16.2\end{array}$ & 105 & 28.6 & 42 & $0.11 \mathrm{NS} \dagger$ \\
\hline Full and free & 83.8 & & 71.41 & & \\
\hline
\end{tabular}

difficult intubation group had a reduced hyoid to chin distance compared with only $34.2 \%$ in the easy intubation group.

There was also no significant association between an increased Mallampatti score, the presence of airway obstruction, or the presence of limited neck mobility and a difficult intubation. Patients with a difficult intubation were more likely to have an obstructed airway ( $14.3 \%$ versus $6.5 \%$ ) and reduced neck mobility (28.6\% versus $16.2 \%$ ) although this did not reach significance.

Table 2 and figure 2 compare the airway assessment scores for the two intubation difficulty groups. Patients in the difficult intubation group had a significantly greater airway assessment score compared with patients in the easy intubation group $(\mathrm{p}<0.05)$. There was also a positive correlation between airway assessment score and intubation grade

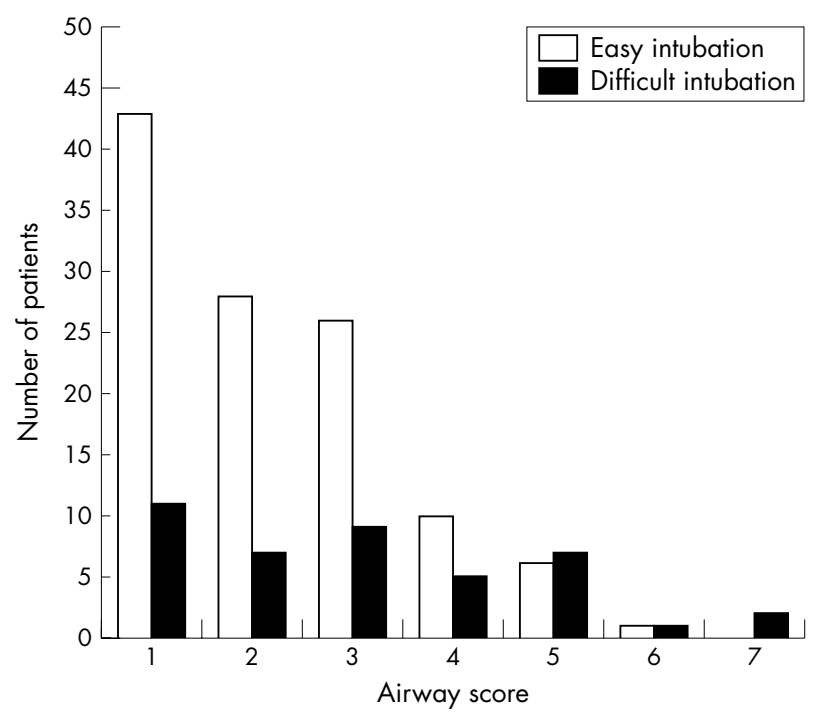

Figure 2 Graph showing number of patients with each airway assessment score in both intubation difficulty groups.
Table 2 Airway assessment scores for the two intubation difficulty groups

\begin{tabular}{|c|c|c|c|c|c|}
\hline \multirow{2}{*}{$\begin{array}{l}\text { Airway } \\
\text { assessment score }\end{array}$} & \multicolumn{2}{|c|}{$\begin{array}{l}\text { Easy intubation } \\
\text { group }\end{array}$} & \multicolumn{2}{|c|}{$\begin{array}{l}\text { Difficult } \\
\text { intubation group }\end{array}$} & \multirow[b]{2}{*}{ p Value } \\
\hline & Number & $\%$ & Number & $\%$ & \\
\hline 0 & 43 & 38 & 11 & 26 & \\
\hline 1 & 28 & 25 & 7 & 17 & \\
\hline 2 & 26 & 23 & 9 & 21 & \\
\hline 3 & 10 & 9 & 5 & 12 & \\
\hline 4 & 6 & 5 & 7 & 17 & \\
\hline 5 & 1 & 1 & 1 & 2 & \\
\hline 6 & 0 & 0 & 2 & 5 & \\
\hline 7 & 0 & 0 & 0 & 0 & \\
\hline 8 & 0 & 0 & 0 & 0 & \\
\hline 9 & 0 & 0 & 0 & 0 & \\
\hline 10 & 0 & 0 & 0 & 0 & \\
\hline Total & 114 & 100 & 42 & 100 & \\
\hline Median & 1.0 & & 2.0 & & \\
\hline$I Q$ range & $0-2.0$ & & $0.3-3.0$ & & $p<0.05^{*} \dagger$ \\
\hline
\end{tabular}

$(r=0.38, \mathrm{p}<0.001)$. Median airway assessment score for the easy intubation groups was 1.0 (interquartile range 0 2.0) compared with 2.0 (interquartile range $0.3-3.0$ ) in the difficult intubation group.

\section{DISCUSSION}

This is the first published study that has attempted to validate the LEMON method in the ED population. We have shown that an airway assessment score based on the LEMON method is able to stratify the risk of intubation difficulty in this population. We have also shown that ED patients with certain airway characteristics are also more likely to have a poor laryngoscopic view. Patients with large incisors, a reduced mouth opening, and a reduced thyroid to floor of mouth distance are all more likely to have a poor view at laryngoscopy. Patients with a reduced hyoid to chin distance, airway obstruction, and reduced neck mobility all have a trend towards poor views, however these factors did not 
Table 3 Proposed revised LEMON based airway assessment score

\begin{tabular}{ll}
\hline Airway assessment score & Points \\
\hline $\begin{array}{l}\text { Number of positive unfavourable } \\
\text { "look" criteria }\end{array}$ & $0-4$ points \\
$\begin{array}{l}\text { Mouth opening less than three finger } \\
\text { breadths }\end{array}$ & 1 point \\
$\begin{array}{l}\text { Hyo-mental distance less than three } \\
\text { finger breadths }\end{array}$ & 1 point \\
$\begin{array}{l}\text { Thyro-hyoid distance less than two } \\
\text { finger breadths }\end{array}$ & 1 point \\
$\begin{array}{l}\text { Presence of an obstructed airway } \\
\text { Presence of poor neck mobility }\end{array}$ & 1 point \\
Total:maximum airway assessment score $=9$, minimum = zero \\
\hline
\end{tabular}

reach significance in this study. A study looking at a larger population may show that these factors are also associated with poor laryngoscopic views.

This study has several limitations. The airway manager performing the LEMON assessment also performed the intubation procedure. This may have led to bias in the subsequent recording of the LEMON characteristics or intubation grade. To assess a large number of intubations, the study aimed to include all intubations carried out in the ED. This could have led to interobserver variability when recording the LEMON characteristics. For example, an inter-incisor distance is measured in finger breadths, which are in turn dependent on the person conducting the test. Other characteristics prone to subjectivity are those of the "look" assessment. Clearly the assessment of a rather vague term such as "large incisors" is highly subjective and is prone to significant interobserver variability. We do not deny that this is the case, however the LEMON method includes the assessment of such characteristics and is designed to be a quick and easy assessment tool. To include complex definitions for such characteristics would defeat the purpose of such a simple, easily remembered ED airway assessment tool. Three "look" characteristics originally described in the LEMON method were removed for this study (see Methods) for similar reasons.

We have defined intubation difficulty based on scores at laryngoscopy. We recognise that laryngoscopic view may be a separate issue to intubation difficulty. Other factors such as the number of separate laryngoscopy attempts made, the length of laryngoscopy attempts, and the number and seniority of airway managers involved have also been described as markers of a difficult intubation. ${ }^{12}$ We chose not to look at these other markers because of their many confounding factors (for example, operator experience), however they could be assessed in future studies.

We have already shown in a previous study that the "look", "obstruction", and "neck mobility" components of the LEMON method are easily assessed in the resuscitation room population. ${ }^{15}$ "Evaluate" criteria could only be fully assessed in $90 \%$ of the resuscitation room population and "Mallampatti" was even less easily assessed being possible in only $57 \%$ of patients.

As we have shown that "Mallampatti" is both difficult to assess and a poor predictor of intubation grade in the ED, it probably has little place in an ED airway assessment score. "Evaluate" criteria are more easily assessed and seem to be predictive of a difficult intubation in the ED population.
We suggest that a LEMON method based airway assessment score (table 3 ) based on four of the five criteria of the LEMON method (all except "Mallampatti"), should be routinely used in the ED to highlight a potentially difficult airway. Use of this score would encourage airway managers to conduct a thorough systematic evaluation of the airway and to readily anticipate problems in its management. If difficulty was predicted early, then more senior help with advanced airway management could be sought.

In conclusion, an airway assessment score based on criteria of the LEMON method is able to successfully stratify the risk of difficult intubation in the emergency department. Patients with a poor laryngoscopic view (grades 2,3 , or 4 ) were more likely to have large incisors, a reduced inter-incisor distance, and a reduced thyroid to floor of mouth distance. They were also more likely to have a higher airway assessment score than those patients with a good larygoscopic view.

\section{CONTRIBUTORS}

Matthew Reed: literature search, study design, interpretation of results, principal investigator, data entry, analysis and reporting of data, writing the paper. Mark Dunn: data collection, data entry, and revision of paper. Dermot McKeown: original idea, literature search, study design, project supervision, and revision of paper.

\section{Authors' affiliations}

M J Reed, M J G Dunn, Emergency Department, Royal Infirmary of Edinburgh, Edinburgh, UK

D W McKeown, Anaesthetic Department, Royal Infirmary of Edinburgh

Funding: none.

Conflicts of interest: none declared.

\section{REFERENCES}

1 Murphy MF, Walls RM. The difficult and failed airway. In: Manual of emergency airway management. Chicago: Lippincott Williams and Wilkins, 2000:31-9.

2 MacKay CA, Terris J, Coats TJ. Prehospital rapid sequence induction by emergency physicians: is it safe? Emerg Med J 2001;18:20-4

3 Graham CA, Beard D, Oglesby AJ, et al. Rapid sequence intubation in Scottish urban emergency departments. Emerg Med J 2003;20:3-5.

4 Wilson ME, Spiegellhalter D, Robertson JA, et al. Predicting difficult intubation. Br J Anaesth 1988;61:211-16.

5 Frerk CM. Predicting difficult intubation. Anaesthesia 1991;46:1005-8.

6 Oates JDL, Macleod AD, Oates PD, et al. Comparison of two methods of predicting intubation difficulty. BrJ Anaesth 1991;66:305-9.

7 Rocke DA, Murray WB, Rout CC, et al. Relative risk analysis of factors associated with difficult intubation in obstetric anesthesia. Anesthesiology 1992;77:67-73.

8 Rose DK, Cohen MM. The airway. Problems and prediction in 18500 patients. Can J Anaesth 1994;41:372-83.

9 Tse JC. Rimm EB. Hussain A. Predicting difficult endotracheal intubation in surgical patients scheduled for general anesthesia: a prospective blind study, Anesth Analg 1995;81:254-8.

10 el-Ganzouri AR, McCarthy RJ, Tuman KJ, et al. Preoperative airway assessment: predictive value of a multivariate risk index. Anesth Analg 1996;82:1197-204.

11 Arne J, Descoins P, Fusciardi J, et al. Preoperative assessment for difficult intubation in general and ENT surgery: predictive value of a clinical multivariate risk index. Br J Anaesth 1998;80:140-6.

12 Saghaei M, Safavi MR. Prediction of prolonged laryngoscopy. Anaesthesia 2001;56:1181-201.

13 Mallampatti SR, Gatt SP, Gugino LD, et al. A clinical sign to predict difficult intubation: a prospective study. Can Anaesth Soc J 1985;32:429-34.

14 Cormack RS, Lehane J. Difficult intubation in obstetrics. Anaesthesia 1984;39:1105-11.

15 Reed MJ, Rennie LM, Dunn MJG, et al. Is the 'LEMON' method an easily applied emergency airway assessment tool? European Journal of Emergency Medicine 2004;11:154-7. 